\title{
Technical note: Quantification of zeins from corn, high-moisture corn, and corn silage using a turbidimetric method: Comparative efficiencies of isopropyl and tert-butyl alcohols
}

\author{
G. Giuberti, A. Gallo, and F. Masoero ${ }^{1}$ \\ Feed and Food Science and Nutrition Institute, Faculty of Agriculture, Università Cattolica del Sacro Cuore, 29100 Piacenza, Italy
}

\begin{abstract}
Zeins are corn endosperm storage proteins that encapsulate starch granules into a protein matrix, which can act as a barrier to starch accessibility and digestion. Laboratory methods to quantify zein are seldom used because they are considered arduous and timeconsuming. A recently published rapid turbidimetric method (mTM) was reinvestigated by changing the solution originally used for the zein solubilization step. In particular, the aim was to explore whether, and to what extent, the use of tert-butyl alcohol $(t-\mathrm{BuOH}-$ $\mathrm{mTM})$ in lieu of isopropyl alcohol ( $i$-PrOH-mTM) was able to improve the quantification of zeins from dry corn, high-moisture corn, and corn silage samples. The nature of the alcohol influenced the zein extraction values, and $t-\mathrm{BuOH}-\mathrm{mTM}$ gave higher zein values in corn (3.6 vs. $3.3 \mathrm{~g} / 100 \mathrm{~g}$ of dry matter) and corn silage samples (1.2 vs. $0.9 \mathrm{~g} / 100 \mathrm{~g}$ of dry matter) compared with $i$-PrOH-mTM. In contrast, similar zein extraction values were obtained for high-moisture corn (2.1 vs. $1.9 \mathrm{~g} / 100 \mathrm{~g}$ of dry matter, respectively). Sodium dodecyl sulfate-PAGE analysis revealed no contamination by nonzein proteins with the use of tert-butyl alcohol. Overall, these findings indicated that tert-butyl alcohol has a greater ability to solubilize zein compared with isopropyl alcohol and thus the $t$-BuOH-mTM allowed greater extraction of zeins. Considering the growing interest of animal nutritionists in zein proteins, such results should provide useful information for routine laboratory analysis.
\end{abstract}

Key words: zein, alcoholic extractant, turbidity, corn

\section{Technical Note}

Zeins are the hydrophobic alcohol-soluble storage prolamins of corn, constituting 44 to $79 \%$ of the corn endosperm proteins (Lawton, 2002). This protein class encapsulates starch into a starch-hydrophobic protein

Received September 29, 2011.

Accepted January 20, 2012.

${ }^{1}$ Corresponding author: francesco.masoero@unicatt.it matrix (Hoffman et al., 2011) that has been defined as a physicochemical barrier to starch accessibility and digestion (Owens et al., 1986; Singh et al., 2010). Moreover, extensive cross-linking of zein subclasses (especially $\beta$ - and $\gamma$-zeins) could yield vitreous endosperm (Hoffman et al., 2011) that has been demonstrated to decrease in situ (Correa et al., 2002) and in vitro (Blasel et al., 2006) starch degradability and in vivo starch digestion (Lopes et al., 2009).

The classical procedure for their quantification consists of sequential exhaustive extractions with aqueous alcohol solutions plus a reducing agent and alkali (Landry and Moureaux, 1970; Hamaker et al., 1995; Landry et al., 2000). However, for routine feed analysis, laboratories seldom use these fractionation assays because they are considered arduous and time-consuming (Larson and Hoffman, 2008).

Alternatively, Larson and Hoffman (2008) recently developed a novel rapid turbidimetric method for quantifying zeins (modified turbidimetric method, mTM), which combined a less laborious procedure with advances in cereal chemistry. Briefly, the mTM quantifies total zein content using turbidity of alcohol-soluble proteins in TCA fit to a standard curve developed with purified zein. Although the mTM was found to be feasible in quantifying zein in ground whole dry corn of varying endosperm types and in high-moisture corns (HMC), the assay tended to yield lower zein values compared with sequential exhaustive extraction methods (Giuberti et al., 2011). It is likely that the aqueous isopropyl alcohol (used in the zein solubilization step by Larson and Hoffman, 2008) was unable to extract all zeins exhaustively (Paulis et al., 1991; Dombrink-Kurtzman and Bietz, 1993). Landry et al. (2002) referenced a more complete extraction of zeins using aqueous tert-butanol; however, the latter has occasionally been used for zein quantification (Esen, 1980b; Landry et al., 2002) but never tested in a turbidimetric method.

Considering the recent interest in analysis of zeins in both corn and corn-based feed samples (Lanzas et al., 2007; Hoffman et al., 2011; Masoero et al., 2011), a possible improvement of the mTM initially proposed 
by Larson and Hoffman (2008) could result in a greater extraction of these proteins and may offer a suitable and a rapid procedure for routine feed analysis.

As a result, the current work was undertaken to reinvestigate the mTM by changing the original solution used for the zein solubilization step. In particular, this study investigated whether, and to what extent, the use of tert-butyl alcohol in lieu of isopropyl alcohol was able to improve the quantification of zeins from dry corn, $\mathrm{HMC}$, and corn silage (CS) samples.

\section{Samples and Chemical Analysis}

A set of 64 commercially available corn and cornbased feed samples (i.e., 24 corn, $20 \mathrm{HMC}$, and 20 CS) was included in this study. These materials were randomly selected from samples sent to the laboratory of the Institute of Food Science and Nutrition (Faculty of Agriculture, Università Cattolica del Sacro Cuore, Piacenza, Italy) for routine analysis.

Samples were dried at $55^{\circ} \mathrm{C}$ for $48 \mathrm{~h}$ in a forced-air oven. All dried samples were then ground through a 1-mm screen using a laboratory mill (Retsch grinder, model ZM1; Brinkman Instruments, Rexdale, ON, Canada) and analyzed for DM, CP, fat (AOAC, 2000), and starch (Masoero et al., 2010) contents. The vitreous endosperm of whole corn kernels was determined by manual dissection (Dombrink-Kurtzman and Bietz, 1993), using the preparation scheme proposed by Correa et al. (2002).

\section{Turbidimetric Method and Sample Preparation}

The operating conditions of the mTM developed by Larson and Hoffman (2008) were rigorously followed. In particular, $1 \mathrm{~g}$ of sample was defatted with acetone $(100 \%)$ for $1 \mathrm{~h}$, filtered through a Buchner funnel, and dried at $55^{\circ} \mathrm{C}$ for $24 \mathrm{~h}$. After drying, the filter was weighed and the acetone-insoluble DM (aiDM) was retained. The DM content of the aiDM was then determined and retained for inclusion in the defatting DM recovery calculation (Larson and Hoffman, 2008).

\section{Zein Solubilization Step}

All samples were analyzed in duplicate in 2 separate runs to evaluate the method precision, and the withinrun zein value was determined as the mean of duplicate samples for the individual run. Specifically, $200 \mathrm{mg}$ of aiDM was weighed in duplicate into $50-\mathrm{mL}$ polystyrene centrifuge tubes. Subsequently, 2 distinct zein-extracting solutions were tested: the first, used as reference and originally proposed by Larson and Hoffman (2008), was an aqueous alcohol solution containing $55 \%$ iso- propyl alcohol $(\boldsymbol{i}$-PrOH$)$ solution plus $0.6 \%$ 2-mercaptoethanol, whereas the second was $60.0 \%$ tert-butanol $(\boldsymbol{t}$-BuOH) solution plus $0.6 \%$ 2-mercaptoethanol.

After $4 \mathrm{~h}$ of mixing, the sample-extractants mixture was centrifuged $(4,500 \times g$ for $20 \mathrm{~min})$, and $0.5 \mathrm{~mL}$ of the supernatant was added to a spectrophotometer tube containing $5.5 \mathrm{~mL}$ of $0.15 \mathrm{M}$ TCA solution and gently mixed using a vortex. The turbidity was allowed to equilibrate for $45 \mathrm{~min}$. Zeins of extracts were quantified by the degree of turbidity measured by absorbance of the unknown sample at $440 \mathrm{~nm}$ on a double-beam spectrophotometer (PerkinElmer, San Jose, CA) against a blank mixture prepared by adding $i-\mathrm{PrOH}$ or $t-\mathrm{BuOH}$ solutions to TCA, respectively. The concentration of zein in the unknown sample was predicted from a standard curve developed with purified zein (Acros Organics, Thermo Fisher Scientific, Waltham, MA), and then the amount of zein $(\mathrm{g} / 100 \mathrm{~g}$ of DM) was calculated by using the equations developed by Larson and Hoffman (2008). Hereafter, $i$-PrOH-mTM and $t$-BuOH-mTM indicate the entire turbidimetric procedures with the use of $i$ - $\mathrm{PrOH}$ and $t-\mathrm{BuOH}$ for the zein solubilization steps, respectively.

\section{Electrophoretic Analysis}

One zein-containing supernatant extracted with $t$ $\mathrm{BuOH}$ solution from corn, $\mathrm{HMC}$, and CS samples was randomly selected and characterized by SDS-PAGE analysis carried out according to the method of Laemmli (1970) using precast 4 to $20 \%$ polyacrylamide gradient gels. A molecular mass marker was purchased from Invitrogen Corp. (Novex Sharp Protein Standard, Grand Island, NY).

\section{Statistical Analysis}

Data were analyzed using Proc GLM (SAS Institute, $2003)$ to estimate the fixed effects of method $(n=2)$ and sample ( $\mathrm{n}=24$ for corn, $\mathrm{n}=20$ each for HMC and CS) for each feed group. Measurements of method precision were obtained by calculating the between-run relative repeatability standard deviation $\left(\mathbf{R S}_{\mathbf{r}}\right.$; Theander et al., 1995; Larson and Hoffman, 2008). The $\mathrm{RS}_{\mathrm{r}}$ was calculated as follows: (between-run repeatability standard deviation/mean value) $\times 100$. Regression analysis was carried out by using Proc REG (SAS Institute, 2003). Significance was declared at $P \leq 0.05$.

\section{Chemical Composition and Zein Quantification}

Average chemical composition and measures of method precision for $\mathrm{CP}$, fat, and starch analyses for each feed group are presented in Table 1. Overall, the 
Table 1. Descriptive statistics and repeatability of DM and some chemical components (CP, fat, and starch) of corn, high-moisture corn (HMC), and corn silage (CS) samples

\begin{tabular}{|c|c|c|c|c|c|}
\hline Feed & Mean & $\mathrm{SD}$ & Minimum & Maximum & $\mathrm{RS}_{\mathrm{r}}{ }^{1}$ \\
\hline \multicolumn{6}{|l|}{ Corn $(\mathrm{n}=24)$} \\
\hline DM, g/100 g & 89.4 & 0.4 & 88.8 & 90.3 & - \\
\hline $\mathrm{CP}, \mathrm{g} / 100 \mathrm{~g}$ of $\mathrm{DM}$ & 8.5 & 1.0 & 6.4 & 9.8 & 1.1 \\
\hline Fat, $\mathrm{g} / 100 \mathrm{~g}$ of $\mathrm{DM}$ & 3.9 & 0.4 & 2.9 & 4.8 & 7.5 \\
\hline Starch, $\mathrm{g} / 100 \mathrm{~g}$ of DM & 68.4 & 1.6 & 65.4 & 71.2 & 2.9 \\
\hline \multicolumn{6}{|l|}{$\operatorname{HMC}(\mathrm{n}=20)$} \\
\hline $\mathrm{DM}, \mathrm{g} / 100 \mathrm{~g}$ & 63.0 & 9.1 & 42.1 & 74.7 & - \\
\hline $\mathrm{CP}, \mathrm{g} / 100 \mathrm{~g}$ of $\mathrm{DM}$ & 8.8 & 0.9 & 7.3 & 10.3 & 1.3 \\
\hline Fat, $\mathrm{g} / 100 \mathrm{~g}$ of $\mathrm{DM}$ & 3.8 & 0.5 & 3.0 & 4.7 & 8.5 \\
\hline Starch, $\mathrm{g} / 100 \mathrm{~g}$ of DM & 67.2 & 2.7 & 60.9 & 72.5 & 3.0 \\
\hline \multicolumn{6}{|l|}{$\operatorname{CS}(\mathrm{n}=20)$} \\
\hline $\mathrm{DM}, \mathrm{g} / 100 \mathrm{~g}$ & 33.9 & 3.9 & 27.3 & 40.7 & - \\
\hline $\mathrm{CP}, \mathrm{g} / 100 \mathrm{~g}$ of $\mathrm{DM}$ & 7.4 & 0.7 & 5.7 & 8.3 & 1.8 \\
\hline Fat, $\mathrm{g} / 100 \mathrm{~g}$ of $\mathrm{DM}$ & 2.8 & 0.3 & 2.0 & 3.2 & 8.5 \\
\hline Starch, $g / 100 \mathrm{~g}$ of DM & 25.1 & 3.6 & 19.4 & 31.3 & 3.6 \\
\hline
\end{tabular}

${ }^{1} \mathrm{RS}_{\mathrm{r}}=$ relative repeatability standard deviation (\% of the mean; Theander et al., 1995).

chemical composition of feeds was consistent with their specific nutrient characteristics. Additionally, the $\mathrm{RS}_{\mathrm{r}}$ values, indicators of method precision (Theander et al., 1995; Giuberti et al., 2011), calculated for CP, fat, and starch analyses (on average $1.4,8.2$, and $3.2 \%$ of the mean, respectively) were in line with previous findings (Mentink and Hoffman, 2006; Spanghero et al., 2010).

Average zein content for each tested feed obtained with the 2 turbidimetric methods, measures of $i$ $\mathrm{PrOH}-\mathrm{mTM}$ and $t$-BuOH-mTM precision, and results of statistical analysis are reported in Table 2. Both method and sample effects influenced the zein content of corn and CS $(P<0.05)$, whereas only the sample effect was significant in HMC. The greatest variation was accounted for by sample effect (being 75.6, 98.0, and $69.8 \%$ of total variation in corn, HMC, and CS, respectively), suggesting that the randomly selected samples had a wide range of zein content. The amount of zein in corn and corn-based feedstuffs depends on several factors, such as genotype differences, stage of maturity, nutritional status of the plant, and ensiling time and process (Landry et al., 2002; Masoero et al., 2011; Hoffman et al., 2011). Overall, the mean zein values of corn, HMC, and CS samples were in line with previous findings (Lásztity, 1984; Drochioiu et al., 2002; Larson and Hoffman, 2008). Additionally, zein contents (mean of $i$-PrOH- and $t-\mathrm{BuOH}-\mathrm{mTM}$ results) of HMC and CS were numerically lower compared with that of dry corn (on average 2.0 and 1.1 vs. $3.5 \mathrm{~g} / 100$ $\mathrm{g}$ of DM, respectively). A lower zein content in HMC and CS compared with that in mature dry corns could be expected, because zein proteins can be degraded by proteolytic activity via the ensiling process (Larson and Hoffman, 2008; Hoffman et al., 2011).

Even if the variation related to method effect was lower than the variation associated with sample effect, it was significant in corn and CS samples $(P<$ 0.05 ), suggesting that $t$-BuOH-mTM improved zein extraction compared with $i$-PrOH-mTM. In particular, the zein content of corn was $3.3 \mathrm{~g} / 100 \mathrm{~g}$ of DM for $i$-PrOH-mTM, whereas a higher mean prolamin content $(3.6 \mathrm{~g} / 100 \mathrm{~g}$ of $\mathrm{DM})$ was obtained (about $10 \% ; P$ $<0.05)$ by using $t$-BuOH-mTM. Considering the zein quantification in CS, the mean zein content quantified with $i$-PrOH-mTM was $0.9 \mathrm{~g} / 100 \mathrm{~g}$ of DM. Similarly, a greater quantification $(1.2 \mathrm{~g} / 100 \mathrm{~g}$ of $\mathrm{DM})$ was obtained

Table 2. Influence of the nature of alcohol in the quantification of zein $(\mathrm{g} / 100 \mathrm{~g}$ of $\mathrm{DM})$ by turbidimetric methods ( $i$-PrOH-mTM and $t$-BuOH-mTM) in corn, high-moisture corn (HMC), and corn silage (CS) samples ${ }^{1}$

\begin{tabular}{|c|c|c|c|c|c|}
\hline \multirow[b]{2}{*}{ Feed sample } & \multicolumn{2}{|c|}{ Method $^{2}$} & \multirow[b]{2}{*}{$\mathrm{RMSE}^{3}$} & \multicolumn{2}{|c|}{ Main effect ( $P$-value) } \\
\hline & $i$-PrOH & $t-\mathrm{BuOH}$ & & Method & Sample \\
\hline Corn & $3.3(6.6)$ & $3.6(7.2)$ & 0.22 & $<0.05$ & $<0.05$ \\
\hline $\mathrm{HMC}$ & $1.9(7.7)$ & $2.1(6.8)$ & 0.42 & 0.18 & $<0.05$ \\
\hline CS & $0.9(12.8)$ & $1.2(9.1)$ & 0.11 & $<0.05$ & $<0.05$ \\
\hline
\end{tabular}

${ }^{1}$ Relative repeatability standard deviation (\% of the mean; Theander et al., 1995) in parentheses.

${ }^{2} i$-PrOH $=55 \%$ 2-propanol $+0.6 \%$ 2-mercaptoethanol; $t$ - BuOH $=60 \%$ tert-butanol $+0.6 \%$ 2-mercaptoethanol.

${ }^{3}$ Root mean square error. 
with $t$-BuOH-mTM (about 25\%; $P<0.05$ ). In HMC, the 2 procedures gave similar average zein values $(1.9$ vs. $2.1 \mathrm{~g} / 100 \mathrm{~g}$ of DM for $i-\mathrm{PrOH}-$ and $t-\mathrm{BuOH}-\mathrm{mTM}$, respectively), despite frequent numerically higher zein values in single $\mathrm{HMC}$ samples obtained with $t$ - $\mathrm{BuOH}-$ mTM compared with the original procedure (ranging from +0.0 to $+12.1 \%$; data not shown). Residual plots ( $t$ - $\mathrm{BuOH}-\mathrm{mTM}$ minus $i$-PrOH-mTM) against the mean zein values measured by the 2 methods are reported in Figure 1 for corn and CS samples. For almost all samples, a higher zein quantification was observed for $t$-BuOH-mTM compared with $i$-PrOH-mTM. However, the differences between $t$-BuOH-mTM and $i$-PrOHmTM tended to decrease with increasing zein contents in $\mathrm{CS}\left(\mathrm{Y}=-0.28 \mathrm{X}+0.57 ; \mathrm{R}^{2}=0.21, P<0.05\right)$, whereas no relationship between method differences and mean zein values was observed for corn $(\mathrm{Y}=-0.04 \mathrm{X}+$ $\left.0.52 ; \mathrm{R}^{2}=0.01, P=0.78\right)$.

Our findings were in line with results in the literature. In particular, Landry et al. (2002), performing an extensive study of the influence of solvents used in the fractionation of corn endosperm proteins, reported a greater percent of the total protein recovered (about $+7 \%$ ) of zein-content extract $\left(\mathrm{E}_{3}\right)$ when $t$ - $\mathrm{BuOH}$ was substituted for $i-\mathrm{PrOH}$. Furthermore, Taylor et al. (1984) showed that aqueous tert-butanol was a better extractant of prolamin compared with isopropyl alcohol in sorghum samples. Two reasonable explanations for these observations exist. First, zeins are highly hydrophobic (Schober et al., 2010) and would be more efficiently dissolved in a less polar solvent than isopropyl alcohol. Second, the extractability of zeins is related both to their extent of aggregation and to interactions between polypeptide chains and polysaccharides (such as cellulose, hemicelluloses, and starch; Lásztity, 1984; $\mathrm{Xu}$ et al., 2007). Probably, the greater solubilization efficiency provided by $t$ - $\mathrm{BuOH}$ compared with $i-\mathrm{PrOH}$ is related to its greater ability to disrupt these bonds due to a greater swelling of starch or other components (Landry et al., 2002). Therefore, considering that absorbance is dependent on zein concentration (Drochioiu et al., 2002), a higher solubilization of zein allowed by $t-\mathrm{BuOH}$ can result in a greater degree of turbidity and thus in improved zein extraction by using the $t-\mathrm{BuOH}-$ mTM procedure.

An SDS-PAGE analysis was carried out to characterize zein protein extracted by $t-\mathrm{BuOH}$ (Figure 2). Overall, based on molecular mass compared with the marker migration lane, the profile of zeins from corn, HMC, and CS samples showed polypeptides corresponding to diverse zein subclasses $(\alpha-, \beta-, \gamma-$, and $\delta$-zeins), thus showing exhaustive zein extraction. Additionally, by visual inspection, zeins formed the typical banding patterns described in previous reports (Wallace et al., 1990; Landry et al., 2002), indicating that these fractions were essentially free of contamination by nonzein proteins.

Recently, Hoffman et al. (2011) reported a more extensive decrease in $\gamma$-zeins (16 and $27 \mathrm{kDa}$ ) than other zein protein subunits, induced by an extended ensiling time $(240 \mathrm{~d})$ in HMC. Although our work was not specifically planned to define the fate of zein protein subunits during ensiling, the spaced bands of 16- and $27-\mathrm{kDa} \gamma$-zeins seem to be less intense in HMC than in corn (lane II versus lane I), perhaps indicating a lower $\gamma$-zein content in the HMC extract. In contrast,
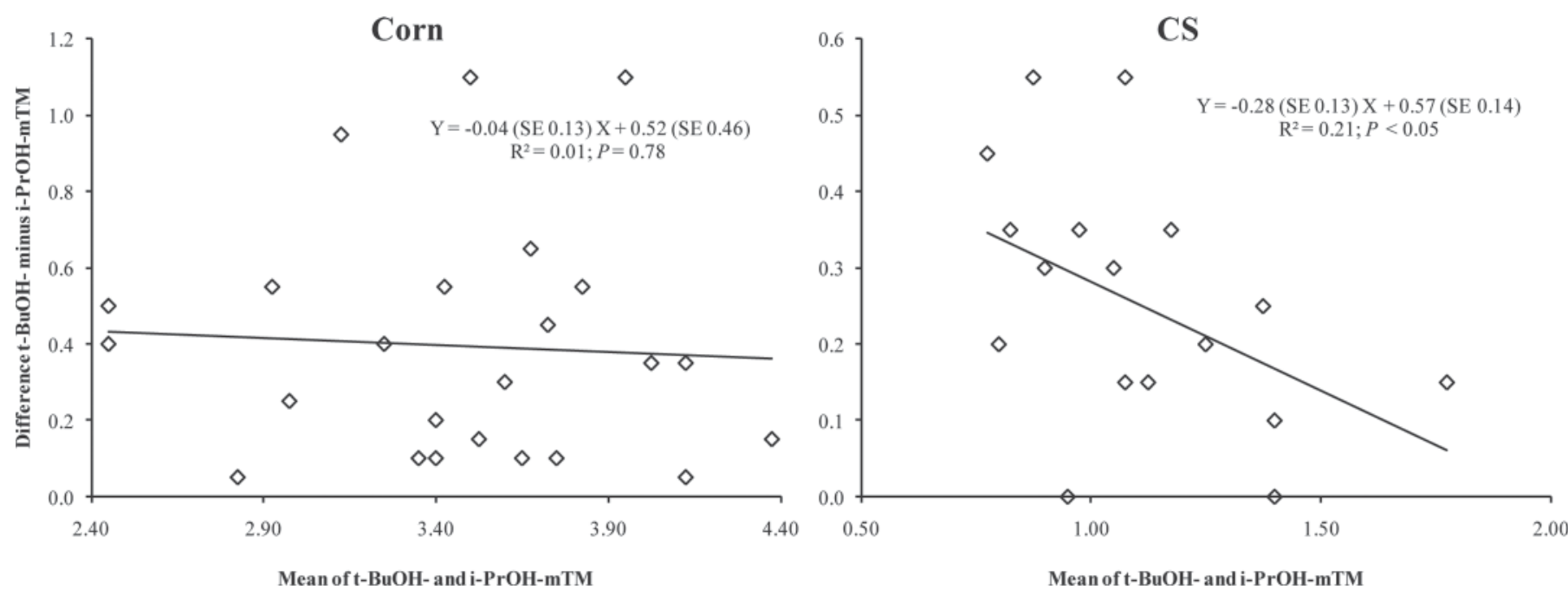

Figure 1. Mean of sample differences of zein content measured using $i$-PrOH-modified turbidimetric method $(\mathrm{mTM})$ and $t$-BuOH-mTM against the mean zein values (g/100 g of DM) measured by 2 methods in corn and corn silage (CS) samples. $i$-PrOH $=55 \% 2$-propanol $+0.6 \%$ 2-mercaptoethanol; $t$ - $\mathrm{BuOH}=60 \%$ tert-butanol $+0.6 \%$-mercaptoethanol. 

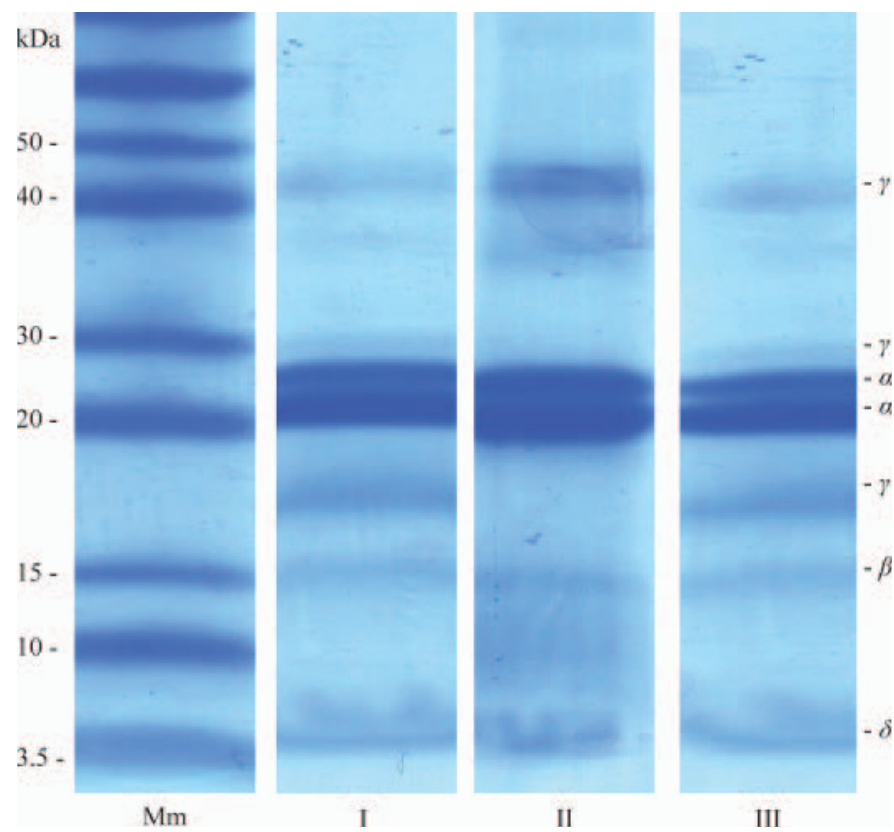

Figure 2. Sodium dodecyl sulfate-PAGE of zeins extracted in the presence of $60 \%$ tert-butanol $+0.6 \%$ 2-mercaptoethanol $(t$-BuOH) Lane $\mathrm{Mm}=$ molecular mass marker (Novex Sharp Protein Standard, Invitrogen Corp., Grand Island, NY); lane I = corn; lane II = highmoisture corn; lane III = corn silage. Positions and molecular masses $(\mathrm{kDa})$ are indicated on the left. Positions of $\alpha-, \beta-, \gamma-$, and $\delta$-zeins are shown on the right. Color version available in the online PDF.

this effect was not observed for CS. We speculate that possible interactions between different sample origins, ensiling times and conditions, solubilization processes, and proteolytic activities could affect the degradation of zeins during ensiling and thus modify the zein subunit profile. Consequently, further studies may be necessary to clarify influence of ensiling and its interaction with different matrices on the zein solubilization process.

Finally, similar $\mathrm{RS}_{\mathrm{r}}$ values were found for both methods for all sample types. In particular, $\mathrm{RS}_{\mathrm{r}}$ was similar between $i$-PrOH-mTM and $t$-BuOH-mTM in corn $(6.6 \%$ vs. $7.2 \%$ of the mean, respectively) and in $\operatorname{HMC}(7.7 \%$ vs. $6.8 \%$ of the mean, respectively), and was slightly higher for $i$-PrOH-mTM compared with $t$-BuOH-mTM in CS samples $(12.8 \%$ vs. $9.1 \%$ of the mean, respectively). In any case, values were comparable to or lower than those originally reported by Larson and Hoffman (2008). Based on the $\mathrm{RS}_{\mathrm{r}}$ values obtained for CP, fat, and starch determinations, both turbidimetric methods were found to be less precise than CP or starch analysis, whereas comparable method precision was observed for fat determination.

From the foregoing results, an additional observation can be made. Some authors (Larson and Hoffman, 2008; Lopes et al., 2009) indicated that zein content could be related to corn vitreousness. Although this study was not specifically designed to test this possible relationship, no agreement between zein content and whole corn kernel vitreousness (ranging from 27.3 to $41.0 \mathrm{~g} / 100 \mathrm{~g}$ of endosperm) was observed for the regression analysis between vitreousness and zein values obtained with $i$-PrOH-mTM and $t$-BuOH-mTM $\left[\mathrm{R}^{2}=\right.$ 0.12 , root mean square error $=3.82, P=0.10$ and $R^{2}=$ 0.05 , root mean square error $=3.99, P=0.32$, respectively]. Likewise, previous work by Landry et al. (2004) found that the total zein content was not significantly related to vitreousness, and data from the recent work of Masoero et al. (2011) pointed to a similar result. Consequently, specific research exploring the possible relationship between zein content and kernel vitreousness is warranted.

In conclusion, for turbidimetric quantification of zein, the use of $t-\mathrm{BuOH}$ can enable a more exhaustive solubilization of zein in corn and CS samples, thus resulting in greater extraction of these proteins. However, $t-\mathrm{BuOH}$ did not improve solubilization of zein in HMC samples, suggesting that additional studies are necessary to clarify possible interference between zein quantification methods and matrix. Moreover, turbidimetric analysis of zein could have both weaknesses and strengths, and a predominant method has not yet been established (Larson and Hoffman, 2008; Giuberti et al., 2011). In particular, interfering components (such as alcohol-soluble lipids or pigments) may yield turbidity (Paulis et al., 1974; Esen, 1980a) and they should be further investigated. The quantification of zein proteins should give a better understanding of factors related to starch degradability and digestion and, consequently, animal performance.

\section{ACKNOWLEDGMENTS}

Authors thank Franco Lucchini of Institute of Microbiology of Università Cattolica Sacro Cuore (Italy) for the technical advice regarding SDS analysis. This project was supported by the AGROSCENARI project "Scenari di adattamento dell'agricoltura italiana ai cambiamenti climatici" of MIPAAF (Ministero delle politiche agricole alimentari e forestali, Italy) and by the Doctoral School of the Agro-Food System (Agrisystem) of the Università Cattolica del Sacro Cuore (Italy).

\section{REFERENCES}

AOAC. 2000. Official Methods of Analysis. 17th ed. Association of Official Analytical Chemists, Gaithersburg, MD.

Blasel, H. M., P. C. Hoffman, and R. D. Shaver. 2006. Degree of starch access: An enzymatic method to determine starch degradation potential of corn grain and corn silage. Anim. Feed Sci. Technol. 128:96-107. 
Correa, C. E. S., R. D. Shaver, M. N. Pereira, J. G. Lauer, and K. Kohn. 2002. Relationship between corn vitreousness and ruminal in situ starch degradability. J. Dairy Sci. 85:3008-3012.

Dombrink-Kurtzman, M. A., and J. A. Bietz. 1993. Zein composition in hard and soft endosperm of maize. Cereal Chem. 70:105-108.

Drochioiu, G., I. Druta, M. N. Petrovanu, and S. Strajeru. 2002. A rapid method used at the Suceava Genebank to evaluate protein quality of some cereal grains. Plant Genet. Resour. Newsl. 129:47-51.

Esen, A. 1980a. A simple colorimetric method for zein determination in corn and its potential in screening for protein quality. Cereal Chem. 57:129-132.

Esen, A. 1980b. Estimation of protein quality and quantity in corn (Zea mays L.) by assaying protein in two solubility fractions. J. Agric. Food Chem. 28:529-532.

Giuberti, G., A. Gallo, and F. Masoero. 2011. A comparison of methods to quantify prolamin contents in cereals. Ital. J. Anim. Sci. 10:7-13.

Hamaker, B. R., A. A. Mohamed, J. E. Habben, C. P. Huang, and B. A. Larkins. 1995. Efficient procedure for extracting maize and sorghum kernel proteins reveals higher prolamin contents than the conventional method. Cereal Chem. 72:583-588.

Hoffman, P. C., N. M. Esser, R. D. Shaver, W. K. Coblentz, M. P. Scott, A. L. Bodnar, R. J. Schmidt, and R. C. Charley. 2011. Influence of ensiling time and inoculation on alteration of the starchprotein matrix in high-moisture corn. J. Dairy Sci. 94:2465-2474.

Laemmli, U. K. 1970. Cleavage of structural proteins during the assembly of the head of bacteriophage T4. Nature 227:680-685.

Landry, J., S. Delhaye, and C. Damerval. 2000. Improved method for isolating and quantitating $\alpha$-amino nitrogen as non-protein, true protein, salt-soluble proteins, zeins, and true glutelins in maize endosperm. Cereal Chem. 77:620-626.

Landry, J., S. Delhaye, and C. Damerval. 2002. Comparative efficiencies of isopropyl and tert-butyl alcohols for extracting zeins from maize endosperm. J. Agric. Food Chem. 50:4131-4134.

Landry, J., S. Delhaye, and C. Damerval. 2004. Protein distribution pattern in floury and vitreous endosperm of maize grain. Cereal Chem. 81:153-158.

Landry, J., and T. Moureaux. 1970. Heterogenicity of the glutelins of the grain core. Selective extraction and composition in amino acids of the three isolated fractions. Bull. Soc. Chem. Biol. 52:1021-1037.

Lanzas, C., D. G. Fox, and A. N. Pell. 2007. Digestion kinetics of dried cereal grains. Anim. Feed Sci. Technol. 136:265-280.

Larson, J., and P. C. Hoffman. 2008. Technical note: A method to quantify prolamin proteins in corn that are negatively related to starch digestibility in ruminants. J. Dairy Sci. 91:4834-4839.

Lásztity, R. 1984. The Chemistry of Cereal Proteins. 2nd ed. CRC Press Inc., Boca Raton, FL.

Lawton, J. W. 2002. Zein: A history of processing and use. Cereal Chem. 79:1-18.
Lopes, J. C., R. D. Shaver, P. C. Hoffman, M. S. Akins, S. J. Bertics, H. Gencoglu, and J. G. Coors. 2009. Type of corn endosperm influences nutrient digestibility in lactating dairy cows. J. Dairy Sci. 92:4541-4548.

Masoero, F., A. Gallo, C. Zanfi, G. Giuberti, and M. Spanghero. 2010. Chemical composition and rumen degradability of three corn hybrids treated with insecticides against the European corn borer (Ostrinia nubilalis). Anim. Feed Sci. Technol. 155:25-32.

Masoero, F., A. Gallo, C. Zanfi, G. Giuberti, and M. Spanghero. 2011. Effect of nitrogen fertilization on chemical composition and rumen fermentation of different parts of plants of three corn hybrids. Anim. Feed Sci. Technol. 164:207-216.

Mentink, R. L., and P. C. Hoffman. 2006. Utility of near infrared reflectance spectroscopy to predict nutritional components in total mixed rations. J. Dairy Sci. 89:2320-2326.

Owens, F. N., R. A. Zinn, and Y. K. Kim. 1986. Limits to starch digestion in the ruminant small intestine. J. Anim. Sci. 63:1634-1648.

Paulis, J. W., J. A. Bietz, R. J. Lambert, and E. M. Villegas. 1991 Identification of modified high-lysine maize genotypes by reversedphase high-performance liquid chromatography. Cereal Chem. 68:361-365.

Paulis, J. W., J. S. Wall, and W. F. Kwolek. 1974. A rapid turbidimetric analysis for zein in corn and its correlation with lysine content. J. Agric. Food Chem. 22:313-317.

SAS Institute. 2003. Guide for Personal Computers. Version 9.2. SAS Inst. Inc., Cary, NC.

Schober, T. J., R. A. Moreau, S. R. Bean, and D. L. Boyle. 2010 Removal of surface lipids improves the functionality of commercial zein in viscoelastic zein-starch dough for gluten-free bread making. J. Cereal Sci. 52:417-425.

Singh, J., A. Dartois, and L. Kaur. 2010. Starch digestibility in food matrix: A review. Trends Food Sci. Technol. 21:168-180.

Spanghero, M., P. Berzaghi, R. Fortina, F. Masoero, L. Rapetti, C. Zanfi, S. Tassone, A. Gallo, S. Colombini, and J. C. Ferlito. 2010. Technical note: Precision and accuracy of in vitro digestion of neutral detergent fiber and predicted net energy of lactation content of fibrous feeds. J. Dairy Sci. 93:4855-4859.

Taylor, J. R. N., L. Schüssler, and W. H. van der Walt. 1984. Fractionation of proteins from low-tannin sorghum grain. J. Agric. Food Chem. 32:149-154.

Theander, O., P. Aman, E. Westerlund, R. Anderson, and D. Petterson. 1995. Total dietary fiber determined as neutral sugar residues, uronic acid residues, and Klason lignin (the Uppsala method): Collaborative study. J. AOAC Int. 78:1030-1044.

Wallace, J. C. M. A. Lopes, E. Paiva, and B. A. Larkins. 1990. New methods for extraction and quantitation of zeins reveal a high content of $\gamma$-zein in modified opaque-2 maize. Plant Physiol. 92:191-196.

$\mathrm{Xu}, \mathrm{W} ., \mathrm{N}$. Reddy, and Y. Yang. 2007. An acidic method of zein extraction from DDGS. J. Agric. Food Chem. 55:6279-6284. 